\title{
PENGARUH EMOTIONAL BRANDING TERHADAP LOYALITAS KONSUMEN (CUSTOMER LOYALTY) DI PERPUSTAKAAN UNIVERSITAS AIRLANGGA SURABAYA
}

\author{
Koko Srimulyo, Aina Mardiyah \\ Universitas Airlangga \\ koko.srimulyo@fisip.unair.ac.id, \\ Aina Mardiyah \\ Universitas Airlangga \\ aina.mardiyah-2016@fisip.unair.ac.id
}

\begin{abstract}
ABSTRAK
Kemajuan teknologi membuat banyak perubahan yang banyak menggeser dan menghilangkan fungsi pekerjaan serta institusi tertentu, tak terkecuali Perpustakaan. Menghadapi perkembangan jaman dengan kemutakhiran teknologi, perpustakaan harus meningkatkan layanan dengan menggunakan pendekatan emosional yang mampu mengikat pengguna (user) dan mempertahankan eksistensinya. Penelitian ini bertujuan untuk mencari hubungan pengaruh antara Emotional Branding terhadap loyalitas pengguna (user). Dengan menggunakan pendekatan kuantitatif-ekplanatif, berusaha menjelaskan hubungan antar variabel independen dan dependen. Penelitian ini menemukan bahwa terdapat adanya hubungan positif dan pengaruh yang signifikan antara emotional branding dan loyalitas.
\end{abstract}

Kata kunci: Emotional branding, Customer Loyalty, Perpustakaan, Universitas Airlangga

\section{PENDAHULUAN}

Lankes (2007) dalam Rubin (2010) mengatakan bahwa perpustakaan memiliki peran krusial untuk meng hubungkan gagasan dari waktu ke waktu, tempat ke tempat, dan juga orang. Pada perkembangan jaman ketika teknologi semakin maju, informasi semakin berkembang pesat dan pendistribusian informasi berjalan begitu cepat, maka orang tak lagi perlu untuk ke perpustakaan guna menemukan informasi yang dibutuhkan. Banyak sumber informasi bisa diakses hanya dari layar HP, di mana pun dan kapan pun. Hal ini menjadi tantangan bagi perpustakaan untuk mempertahankan eksistensinya. Untuk mampu terus bertahan di tengah perkembangan jaman dan kemajuan teknologi, maka perpustakaan harus mengembangkan layanan yang dimiliki, dengan cara memahami bagaimana dan mengapa orang menggunakan informasi. Dengan begitu, upaya pengembangan terfokus pada kebutuhan pengguna. Hanya dengan upaya seperti itulah, perpustakaan dapat mengikat dan mempertahankan konsumennya (Rubin, 2010).

Dalam industri fesyen, emotional branding telah banyak digunakan untuk mengikat konsumen pada merek. Kemajuan teknologi berdampak pada semakin banyaknya merek dalam pasar yang terus berubah, sehingga masing-masing merek harus memiliki strategi 
untuk membuat customernya tetap loyal, yaitu dengan cara meningkatkan kualitas pelayanan yang berfokus pada customer atau pemustaka dan sekaligus membedakan dirinya dari merek lain (Kim \& Sullivan, 2019). Pada beberapa penelitian terdahulu, hasil positif didapat ketika menguji pengaruh emotional branding terhadap loyalitas konsumen suatu merek.

Pengaruh emotional branding pada kesetiaan konsumen, meski banyak digunakan di dunia marketing, namun belum pernah ditemukan ada di institusi penyedia jasa seperti perpustakaan, padahal keduanya sama-sama berorientasi pada kebutuhan konsumen atau pengguna. Untuk itu, dalam studi ini dilakukan uji pengaruh emotional branding terhadap kesetiaan atau loyalitas pemustaka di perpustakaan.

Pada perkembangannya, perpustakaan beralih dari yang mulanya hanya memberikan layanan jasa peminjaman buku menjadi institusi yang berfokus pada kenyamanan pemustaka. Perpustakaan seperti yang telah disebutkan di atas, dituntut untuk mampu berubah dengan berfokus untuk memenuhi kebutuhan pemustaka akan informasi, serta memberikan kenyamanan. Meski begitu, tak semua perpustakaan bergerak mengarah pada pemustaka oriented. Beberapa lainnya, masih berfokus pada koleksi buku. Hal ini terjadi pada perpustakaan-perpustakaan kecil di daerah. Perpustakaan Kampus B Universitas Airlangga dipilih untuk dijadikan lokasi pengujian karena memiliki kualifikasi pelayanan, desain, dan juga fasilitas yang sesuai dengan strategi emotional branding. Dalam prakteknya, perpustakaan Kampus B Universitas Airlangga memiliki layanan konsultasi untuk mahasiswa yang menempuh skripsi, tesis, maupun disertasi. Dalam hal penyediaan fasilitas pendukung, Perpustakaan Kampus B Universitas Airlangga juga mengutamakan kebutuhan pengguna, hal itu dapat dilihat dengan adanya beberapa bagian dalam gedung yang dipisah guna untuk mengakomodasi setiap kegiatan mahasiswa seperti ruangan yang memfasilitasi mahasiswa untuk belajar dengan memberikan sekat-sekat pada meja, menyediakan stop kontak untuk kebutuhan akan listrik, fasilitas wifi untuk akses internet, dan akses untuk jurnal di laman resmi universitas airlangga. Perpustakaan Kampus B Universitas Airlangga bahkan menyediakan ruang belajar bagi individu agar merasa lebih nyaman dalam belajar. Tidak hanya itu, ruangan untuk berdiskusi juga ditelakkan di tempat terpisah agar mahasiswa tetap bisa bertukar pikiran satu sama lain tanpa mengganggu pengguna yang sedang berfokus belajar sendiri.

Perpustakaan Kampus B Universitas Airlngga juga memfasilitasi desain yang membuat pengguna merasakan suasana lain ketika berada di dalamnya. Ada beberapa spot atau bagian di dalam Perpustakaan yang merupakan hasil kerjasama Perpustakaan dengan kedutaan beberapa negara seperti Amerika, Inggris, dan Perancis. Untuk itu, ada spot yang dinamakan American Corner, Great Britain Corner, dan juga Warung Perancis. Masingmasing spot tersebut didesain khas negara partner dengan aksesoris bendera, literature sejarah dan bahkan karya penulis-penulis asal negara partner. Hal tersebut dilakukan untuk memberikan pengalaman bagi pengguna ketika berkunjung ke Perpustakaan Kampus B Universitas Airlangga.

Dalam studi ini, pengujian dilakukan untuk mengetahui pengaruh emotional branding terhadap loyalitas pengguna pada Perpustakaan Kampus B Universitas Airlangga. Apakah ada pengaruh positif seperti yang terjadi pada produk merek tertentu dalam penelitianpenelitan sebelumnya? Lalu, diajukan dua pertanyaan utama untuk dijawab. 
A. Apakah emotional branding yang terdiri dari hubungan, pengalaman pancaindra, imajinasi secara simultan berpengaruh terhadap loyalitas konsumen di Perpustakaan Kampus B Universitas Airlangga Surabaya?

B. Apakah emotional branding yang terdiri dari hubungan, pengalaman pancaindra, imajinasi secara parsial berpengaruh terhadap loyalitas konsumen di Perpustakaan Kampus B Universitas Airlangga Surabaya?

\section{TINJAUAN PUSTAKA}

\section{Emotional Branding dan Perpustakaan}

Emotional branding sendiri memang hal baru dalam komunikasi pemasaran, yakni mengacu pada sebuah praktik untuk membangun merek dan perusahaan melalui emosi atau perasaan, kebutuhan, keinginan, keyakinan, dan aspirasi konsumen (Pogorzelski, 2018). Emotional branding mulanya dikenalkan oleh Marc Gobe yang berfokus pada studi mengenai emosi. Beberapa karya sebelumnya adalah Making The Emotional Connection (2001) dan Emotional Identity (2003), keduanya berfokus membahas tentang emosi manusia. Setelahnya, Gobe mengemukakan hal baru yang disebut Emotional Branding yang menghubungkan merek dengan pelanggannya (Marc Gobe, n.d.). Dalam penjelaskan Gobe, ia mengatakan bahwa barang dan jasa saja tak cukup untuk menarik konsumen, maka kuncinya adalah haruslah ada aspek emosional pada produk dan pendistribusiannya. Emosional yang dimaksud di sini adalah bagaimana suatu merek dapat menggugah emosi konsumen; bagaimana suatu merek menjadi hidup bagi masyarakat, dan membentuk hubungan yang mendalam dan tahan lama (Marc Gobe, n.d.).

Emotional branding dapat dikatakan berhasil apabila memicu respon yang datang dari konsumen, seperti rasa ingin yang kuat untuk menggunakan suatu produk (Pogorzelski, 2018). Untuk dapat memandapatkan emotional branding, pertama yang harus dilakukan adalah mengenali pendekatan emosi-kognisi. Kedua, mengidentifikasi kunci untuk memposisikan merek ke dalam inti kehidupan pelanggan dan menciptakan kesesuaian diri dengan memungkinkan konsumen untuk mengidentifikasi dirinya dengan merek. Ketiga, mengembangkan kerangka kerja tentang anteseden dan konsekuensi dari strategi branding emosional yang sukses dan berkelanjutan (Akgün et al., 2013) Pada penelitian lain dikatakan bahwa manajemen pengalaman pelanggan sangat penting untuk menghasilkan emosi yang menyenangkan, yang penyampaiannya harus dilihat dari segi holistic. Pengalaman pelanggan memainkan peran penting dalam pembentukan emosi positif, yang antara lain dipicu oleh kepuasan pelanggan, kepercayaan, dan komitmen untuk mengembangkan loyalitas sejati (Saini \& Singh, 2017).

Emotional branding jika diterapkan di perpustakaan merupakan bentuk strategi atau upaya branding dengan menjaga hubungan yang emosional yang mendalam, dekat atau intens dengan pengguna perpustakaan agar para pengguna perpustakaan mengalami pengalaman yang tidak terduga dan selalu membekas di benak pengguna perpustakaan.

Proses emotional branding didasarkan pada empat pilar penting (Gobe, 2005), yaitu hubungan, pengalaman pancaindra, imajinasi dan visi.

a. Hubungan: Hubungan merupakan tentang penciptaan hubungan yang erat atau intim dengan menumbuhkan rasa hormat dan menghargai serta memberikan pengalaman emosional yang diinginkan oleh pemustaka. Hubungan yang dibangun 
oleh perpustakaan dan juga pustakawan kepada pemustaka harus memperhatikan karakteristik pemustaka, yaitu dengan melihat tren, sikap, dan juga perilaku konsumen.

b. Pengalaman pancaindra: Pengalaman pancaindra di perpustakaan merupakan pengalaman para pengguna yang dirasakan melalui pancaindera mereka saat berkunjung dan memanfaatkan ruangan dan fasilitas yang ada di perpustakaan. Beberapa komponen dalam merangsang pancaindera adalah bunyi yang membawa suasana, warna yang menghipnotis/simbol yang memikat, rasa yang menggiurkan, bentuk yang dapat disentuh, dan aroma yang menggoda

c. Imajinasi: Fisik perpustakaan maupun layout web haruslah memiliki desain yang berbeda, sehingga menimbulkan pengalaman baru bagi pemustaka. Bagian paling penting adalah bahwa desain tersebut harus mampu menarik hari para pengguna.

d. Visi: Visi adalah gambaran masa depan, seperti gambaran keunggulan, dimana orang, tim, atau organisasi ingin menciptakan masa depan terbaiknya (Papulova, 2014). Pada penelitian ini, pilar visi tidak digunakan, karena tidak semua konsumen atau pengguna mengetahui secara pasti visi dari sebuah perusahaan.

\section{Loyality}

Loyality atau loyalitas, dalam Bahasa Indonesia dimaknai sebagai kesetiaan. Kesetiaan dalam perpustakaan adalah respon perilaku seperti mengunjungi kembali perpustakaan melalui keputusan mengenai penggunaan kembali layanan perpustakaan yang diberikan (Tajedini et al., 2020). Respon ini disebabkan oleh pola pikir pelanggan yang memiliki sikap positif terhadap perpustakaan, memiliki komitmen untuk menggunakan kembali layanan yang ada di perpustakaan, dan merekomendasikan layanan tersebut kepada orang lain.

\section{METODE PENELITIAN}

Studi dalam penelitian ini menggunakan pendekatan kuantitatif-eksplanatif. Ini karena kuantitatif-eksplanatif dapat menggambarkan hubungan sebab-akibat yang dibutuhkan untuk mencari hubungan keterkaitan emotional branding dengan loyalitas pemustaka. Selain itu, kuantitatif-eksplanatif juga memang ditujukan untuk menghubungan pola-pola yang beragam, namun memiliki satu keterikatan (Priyono, 2012). Penelitian ini dilakukan di Perpustakaan Kampus B Universitas Airlangga karena Perpustakaan Kampus B Universitas Airlangga dianggap sebagai perpustakaan yang pemustaka oriented seperti yang telah disebutkan di paragraph sebelumnya.

Populasi dalam penelitian ini adalah mahasiswa aktif Kampus B Universitas Airlangga yang merupakan pengguna dari perpustakaan Kampus B Universitas Airlangga. Studi ini menggunakan purposive sampling sebagai teknik pengambilan sample dengan mengambil sampel sebanyak 100 (Priyono, 2012). Teknik tersebut dianggap sesuai dengan keadaan penelitian, yang tidak diketahui banyak pengunjung rutin yang merupakan Mahasiswa Universitas Airlangga, untuk itu penelitian mensyaratkan kriteria responden. Kriteria responden yang ditetapkan di dalam penelitian ini adalah mahasiswa Universitas Airlangga yang rutin berkunjung ke kampus B setidaknya 3 kali dalam satu minggu. Jumlah responden ditentukan dengan menggunakan rumus hitungan sebagai berikut: 
$n=\frac{1}{4}\left(\frac{Z a / 2}{e}\right)_{2}$

$\mathrm{n}=$ Jumlah sampel

$\mathrm{Z}$ = Angka yang menunjukkan penyimpangan suatu nilai variabel dari mean dihitung dalam satuan standar deviasi tertentu

E : Error (Kesalahan)

Nilai signifikansi di dalam penelitian ini adalah 0,05 sehingga tingkat kesalahan tidak lebih dari 10 persen $(\%)$

$$
\begin{aligned}
& n=\frac{1}{4}\left(\frac{Z a / 2}{0.1}\right)^{2} \\
& n=\frac{1}{4}\left(\frac{1,96}{0.1}\right)^{2} \\
& =96.04
\end{aligned}
$$

Dari penghitungan data di atas, maka sampel minimal yang harus dicapai untuk memperoleh gambaran yang presisi adalah 94.04, maka peneliti memutuskan untuk mengambil 100 sampel, selain juga karena merupakan jumlah yang disepakati oleh kebanyakan peneliti (Priyono, 2012) (Unaradjan \& Sihotang, 2019), selain data primer yang didapat dari hasil respon yang diberikan narasumber dalam kuesioner, sumber lain yang digunakan dalam penelitian ini adalah dokumen pendukung (sekunder) yang menerangkan keadaan lapangan dan juga hasil observasi.

Studi ini menggunakan nilai reliability coefficient alpha. Item pada masing-masing pengukuran dikatakan reliabel apabila memiliki nilai koefisien alfa lebih besar dari 0,6 (Kahle \& Malhotra, 1994). Untuk itu, masing-masing item diberikan opsi yang memiliki skor dengan mengacu pada skala likert.

$$
\begin{aligned}
& 1=\text { sangat tidak setuju } \\
& 2=\text { tidak setuju } \\
& 3=\text { cukup } \\
& 4=\text { setuju } \\
& 5=\text { sangat setuju }
\end{aligned}
$$

Sebelum memasukkan kategori ke dalam rumus, maka dilakukan pencarian interval dengan cara sebagai berikut:

$$
\frac{\text { Skor Tertinggi-Skor Terendah }}{\text { Banyaknya bilangan }}=\frac{5-1}{5}=0.8
$$

Sugiyono (2014) memberikan skor pada masing-masing kategori dengan nilai sebagai berikut:

$\begin{array}{ll}\text { Skor kategori sangat tinggi } & =4.21-5.00 \\ \text { Skor kategori tinggi } & =3.41-4.20 \\ \text { Skor kategori sedang } & =2.61-3.40 \\ \text { Skor kategori rendah } & =1.81-2.60 \\ \text { Skor kategori sangat rendah } & =1.00-1.80\end{array}$

Sedangkan untuk mengetahui hubungan keterkaitan, maka harus ditentukan tingkatan hubungan: rendah atau tinggi. Dalam penelitian kuantitatif, segala hal terukur, sehingga mengukurnya digunakan pedoman (Sugiyono, 2014) sebagai berikut : 
Tingkat hubungan sangat rendah

$$
\begin{aligned}
& =0.00-0.1999 \\
& =0.20-3.99 \\
& =0.40-0.599 \\
& =0.60-0.799
\end{aligned}
$$

$$
\text { Tingkat hubungan sangat kuat } \quad=0.80-1.000
$$

Ada 4 pengujian asumsi yang dilakukan di dalam penelitian ini. Pertama, uji multikolinieritas yang bertujuan untuk mengetahui korelasi antar variable independen. Hasil dikatakan baik jika tidak ditemukan korelasi antar variable independen. Sebaliknya, jika terbukti memiliki hubungan yang kuat, maka terdapat multikolinieritas pada kedua variabel tersebut (Santoso, 2019). Kedua, uji asumsi normalitas dilakukan agar mengetahui nilai residual berdistribusi normal atau tidak normal karena berpengaruh pada populasi. Berikut merupakan hipotesis pengujian asumsi normalitas:

$\mathrm{H}_{0}$ : Residual berdistribusi normal

$\mathrm{H}_{1}$ : Residual tidak berdistribusi normal. Kriteria pengujian dinyatakan berdistribusi normal apabila nilai significant alpha 5\% atau 0,05 (Herlina, 2019). Ketiga, uji asumsi heteroskedastisitas dilakukan dengan tujuan untuk mengetahui residual memiliki ragam yang homogen atau tidak. Untuk membuktikannya, ada beberapa metode yang tersedia, namun dalam penelitian ini digunakan glejser test dan grafik sactterplot.

Berikut adalah hipotesis pengujian asumsi heteroskedastisitas:

$\mathrm{H}_{0} \quad$ : Residual memiliki ragam homogen

$\mathrm{H}_{1} \quad$ : Residual tidak memiliki ragam homogen

Residual dinyatakan memiliki ragam homogen apabila nilai probabilitas $\geq$ level of significant $(\alpha=5 \%)$ (Ghozali; 2013). Setelah melakukan uji asumsi, maka dilakukan pengujian hipotesis yang diputuskan dalam penelitian ini menggunakan analisis korelasi Rank Spearman. Korelasi Rank Spearman ini digunakan untuk mengukur erat atau tidaknya hubungan antar dua variabel (Furfey \& Siegel, 1957). Langkah pengukuran sebagai berikut:

1. Pemberian jenjang pada nilai pengamatan dari dua variabel yang diukur korelasinya

2. Setiap pasang jenjang dihitung perbedaannya $\left(d_{i}\right)$

3. Perbedaan setiap pasang jenjang tersebut dikuadratkan dan dihitung jumlahnya $\left(\sum d_{i}^{2}\right)$

4. Harga koefisien korelasi rank Spearman dapat dihitung dengan rumus:

$r_{s} \quad=$ koefisien korelasi (rho spearman)

$\mathrm{n} \quad=$ jumlah sampel

$d_{1} \quad=$ selisih rangking dari kedua variabel yang diteliti

Hipotesis yang digunakan dalam penelitian ini adalah:

a. $\mathrm{H}_{0}$ menyatakan bahwa tidak ada pengaruh yang signifikan antara variabel bebas $\mathrm{X}$ (emotional branding) terhadap variabel terikat Y (loyalitas konsumen)

b. $\mathrm{H}_{1}$ menyatakan bahwa ada pengaruh yang signifikan antara variabel bebas $\mathrm{X}$ (emotional branding) terhadap variabel terikat Y (loyalitas konsumen)

c. Bila tingkat signifikansi t hitung $<$ Level of signifikansi $\alpha=0,05$ maka $\mathrm{H}_{1}$ diterima atau $\mathrm{H}_{0}$ ditolak 
d. Bila tingkat signifikansi t hitung $>$ Level of signifikansi $\alpha=0,05$ maka $\mathrm{H}_{0}$ diterima atau $\mathrm{H}_{1}$ ditolak

e. Nilai signifikansi

\section{HASIL DAN PEMBAHASAN}

Joel Desgrippes dalam (Marc Gobe, n.d.) mengungkapkan bahwa sebuah merek menyangkut keterikatan emosional dengan masyarakat dalam kehidupan sehari - hari, dalam hal ini dapat dikatakan bahwa emosi atau perasaan konsumen terhadap suatu merek berarti bagaimana suatu merek dapat membangkitkan perasaan konsumen, dan bagaimana perusahaan / merek dapat membentuk sebuah hubungan yang erat dan dalam jangka waktu yang lama dengan konsumen. Hubungan ini tentu saja dijaga oleh pola pikir positif yang dimiliki oleh konsumen terhadap merek sehingga membawa konsumen kembali pada merek yang sama secara terus menerus, dan bahkan merekomendasikannya. Itu pula yang terjadi pada pemustaka pengguna perpustakaan, mereka yang memiliki hubungan baik (positif) dengan perpustakaan, akan berkunjung secara rutin, dan bahkan merekomendasikan perpustakaan tersebut pada orang lain, berikut adalah hasil dan pembahasan data penelitian ini:

\section{- Karakteristik User Perpustakaan Kampus B Universitas Airlangga}

Dalam penelitian di lapangan, sebanyak 100 Responden yang melakukan pengisian survey. Karakteristik Responden yang merupakan Pemustaka perpustakaan Kampus B Universitas Airlangga disajikan terpisah dengan mendasar pada jenis kelamin, jenjang pendidikan, dan intensitas kunjungan. Dari jenis kelamin, Pemustaka perpustakaan Kampus B Universitas Airlangga didominasi oleh perempuan dengan perolehan 82\%, sedangkan pemustaka laki-laki sebanyak 18\%. Pada kategori tingkat pendidikan, S1 mendapat hasil paling dominan, yaitu sebanyak 91\% sedang mahasiswa D3 sebanyak 9\%. Berdasarkan intensitas kunjungannya, 76\% responden mengaku mengunjungi perpustakaan sebanyak 3-4 kali dalam satu minggu, sedangkan 24\% lain mengaku berkunjung lebih dari 4 kali dalam seminggu.

\section{- Persepsi Responden}

Berdasarkan data yang didapatkan, maka dibuat satu table yang memuat persepsi responden pada variabel emotional branding. Berikut table I:

Tabel I

Persepsi Responden Pada Variabel Emotional Branding

\begin{tabular}{|c|c|c|c|}
\hline No & Pernyataan & Rata-Rata & Keterangan \\
\hline \multicolumn{2}{|c|}{$\mathrm{X}_{1}=$ Aspek Hubungan } \\
\hline
\end{tabular}




\begin{tabular}{|c|c|c|c|}
\hline 1 & $\begin{array}{l}\text { Saya merasa bahwa pustakawan perpustakaan } \\
\text { Universitas Airlangga memberikan pelayanan yang baik } \\
\text { kepada pengguna }\end{array}$ & 4,010 & Tinggi \\
\hline 2 & $\begin{array}{l}\text { Saya merasa bahwa pustakawan perpustakaan } \\
\text { Universitas Airlangga selalu memberikan senyum, salam, } \\
\text { sapa kepada pengguna }\end{array}$ & 3,540 & Tinggi \\
\hline 3 & $\begin{array}{l}\text { Saya merasa bahwa pustakawan perpustakaan } \\
\text { Universitas Airlangga memiliki sikap sopan dan santun } \\
\text { kepada pengguna }\end{array}$ & 3,930 & Tinggi \\
\hline 4 & $\begin{array}{l}\text { Saya merasa bahwa sikap ramah yang diberikan } \\
\text { Pustakawan Perpustakaan Universitas Airlangga mampu } \\
\text { menciptakan suasana yang nyaman saat menggunakan } \\
\text { layanan di perpustakaan }\end{array}$ & 4,130 & Tinggi \\
\hline 5 & $\begin{array}{l}\text { Saya merasa bahwa Pustakawan Perpustakaan } \\
\text { Universitas Airlangga sigap dalam membantu pengguna } \\
\text { yang mengalami kesulitan dalam mencari sumber informasi }\end{array}$ & 3,870 & Tinggi \\
\hline 6 & $\begin{array}{l}\text { Saya merasa bahwa Pustakawan Perpustakaan } \\
\text { Universitas Airlangga berusaha untuk mengetahui } \\
\text { kebutuhan pengguna dengan bertanya langsung pada } \\
\text { pengguna }\end{array}$ & 3,330 & Sedang \\
\hline 7 & $\begin{array}{l}\text { Saya merasa bahwa Pustakawan Perpustakaan } \\
\text { Universitas } \\
\text { pengguna }\end{array}$ & 3,780 & Tinggi \\
\hline 8 & $\begin{array}{l}\text { Saya merasa bahwa Pustakawan Perpustakaan } \\
\text { Universitas Airlangga telah menyediakan koleksi yang } \\
\text { cukup lengkap, baik dari segi koleksi digital ataupun cetak }\end{array}$ & 3,640 & Tinggi \\
\hline 9 & $\begin{array}{l}\text { Saya merasa bahwa Pustakawan Perpustakaan } \\
\text { Universitas Airlangga telah melayani pengguna dengan } \\
\text { cepat dan tepat }\end{array}$ & 3,740 & Tinggi \\
\hline 10 & $\begin{array}{l}\text { Saya merasa bahwa Pustakawan Perpustakaan } \\
\text { Universitas Airlangga selalu memberikan informasi baru } \\
\text { (up to date) kepada pengguna, baik secara offline maupun } \\
\text { online }\end{array}$ & 3,680 & Tinggi \\
\hline 11 & $\begin{array}{l}\text { Saya merasa bahwa Pustakawan Perpustakaan } \\
\text { Universitas Airlangga sudah berinteraksi dengan baik dan } \\
\text { aktif kepada para pengguna secara offline maupun online }\end{array}$ & 3,750 & Tinggi \\
\hline 12 & $\begin{array}{l}\text { Saya merasa bahwa Pustakawan Perpustakaan } \\
\text { Universitas Airlangga masih mempertahankan sumber } \\
\text { informasi untuk generasi tua (baby boomers), mis. } \\
\text { kebutuhan koleksi cetak }\end{array}$ & 3,860 & Tinggi \\
\hline 13 & $\begin{array}{l}\text { Saya merasa bahwa Pustakawan Perpustakaan } \\
\text { Universitas Airlangga mampu menyesuaikan kebutuhan } \\
\text { sumber informasi untuk generasi muda (generasi x dan y), } \\
\text { mis. Kebutuhan digital }\end{array}$ & 3,770 & Tinggi \\
\hline & Total Mean & 3.771 & Tinggi \\
\hline & $\mathrm{X} 2=$ Aspek Pengalaman Pancainc & & \\
\hline 14 & $\begin{array}{l}\text { Saya merasa bahwa layanan music coustic di waktu } \\
\text { tertentu dapat dinikmati oleh pengguna saat berada di } \\
\text { Perpustakaan Universitas Airlangga }\end{array}$ & 3,820 & Tinggi \\
\hline
\end{tabular}




\begin{tabular}{|c|c|c|c|}
\hline & $\begin{array}{l}\text { Saya merasa bahwa layanan music coustic yang ada di } \\
\text { Perpustakaan Universitas Airlangga mampu menciptakan } \\
\text { suasana santai kepada pengguna }\end{array}$ & 3,960 & Tinggi \\
\hline 16 & $\begin{array}{l}\text { Saya merasa bahwa Perpustakaan Universitas Airlangga } \\
\text { memiliki warna interior yang bagus dan nyaman untuk } \\
\text { dilihat }\end{array}$ & 4,050 & Tinggi \\
\hline 17 & $\begin{array}{l}\text { Saya merasa bahwa pemilihan warna interior di } \\
\text { Perpustakaan Universitas Airlangga mampu menciptakan } \\
\text { suasana yang betah dan nyaman saat berada di perpustakaan }\end{array}$ & 4,140 & Tinggi \\
\hline 18 & $\begin{array}{l}\text { Saya merasa bahwa Perpustakaan Universitas Airlangga } \\
\text { memiliki pencahayaan ruangan yang baik }\end{array}$ & 4,160 & Tinggi \\
\hline 19 & $\begin{array}{l}\text { Saya merasa bahwa pemilihan warna situs web } \\
\text { Perpustakaan Universitas Airlangga sudah bagus dan } \\
\text { cocok }\end{array}$ & 3,900 & Tinggi \\
\hline 20 & $\begin{array}{l}\text { Saya merasa bahwa Pustakawan Perpustakaan } \\
\text { Universitas Airlangga menyediakan fasilitas lemari } \\
\text { minuman dingin untuk memenuhi kebutuhan pengguna saat } \\
\text { berada di dalam perpustakaan }\end{array}$ & 3,980 & Tinggi \\
\hline 21 & $\begin{array}{l}\text { Saya merasa bahwa Perpustakaan Universitas Airlangga } \\
\text { memiliki ruangan yang sejuk, bersih dan terawat }\end{array}$ & 4,330 & Sangat Tinggi \\
\hline 22 & $\begin{array}{l}\text { Saya merasa bahwa Perpustakaan Universitas Airlangga } \\
\text { memiliki interior (mis. Rak, meja, kursi, dll) yang bersih } \\
\text { dan terawat }\end{array}$ & 4,190 & Tinggi \\
\hline 23 & $\begin{array}{l}\text { Saya merasa bahwa Perpustakaan Universitas Airlangga } \\
\text { memiliki kursi/sofa dan karpet yang empuk dan nyaman }\end{array}$ & 4,260 & Sangat Tinggi \\
\hline & Total Mean & 4.079 & Tinggi \\
\hline \multicolumn{4}{|c|}{$\mathrm{X}_{3}=$ Aspek Imajinasi } \\
\hline 24 & $\begin{array}{l}\text { Saya merasa bahwa desain interior yang digunakan di } \\
\text { ruang Perpustakaan Universitas Airlangga memiliki desain } \\
\text { yang bagus dan indah }\end{array}$ & 4,040 & Tinggi \\
\hline 25 & $\begin{array}{l}\text { Saya merasa bahwa desain interior di Perpustakaan } \\
\text { Universitas Airlangga } \\
\text { perkembangan zaman }\end{array}$ & 3,840 & Tinggi \\
\hline 26 & $\begin{array}{l}\text { Saya merasa bahwa desain dan tata ruang yang } \\
\text { ditampilkan di ruang Perpustakaan Universitas Airlangga } \\
\text { mampu menciptakan suasana betah dan nyaman }\end{array}$ & 4,140 & Tinggi \\
\hline 27 & $\begin{array}{l}\text { Saya merasa bahwa desain situs web Perpustakaan } \\
\text { Universitas Airlangga memiliki desain yang simpel dan } \\
\text { bagus }\end{array}$ & 3,840 & Tinggi \\
\hline 28 & $\begin{array}{l}\text { Saya merasa bahwa desain situs web Perpustakaan } \\
\text { Universitas Airlangga nyaman untuk dilihat }\end{array}$ & 3,920 & Tinggi \\
\hline & Total Mean & 3.956 & Tinggi \\
\hline & Mean Variabel Keseluruhan & 3,914 & Tinggi \\
\hline
\end{tabular}

Dari table di atas, dapat diketahui bahwa persepsi responden terhadap variabel (X), yaitu Emotional Branding dengan mengajukan 28 pertanyaan secara keseluruhan menghasilkan rata-rata sebesar 3,914 dan berada pada kategori tinggi. Persepsi paling tinggi yang diberikan 
responden adalah persepsi mengenai pengalaman pancaindera dengan indikator bahwa Perpustakaan Kampus B Universitas Airlangga memiliki ruangan yang sejuk, bersih, dan terawatt. Penilaian kategori tersbeut memiliki rata-rata 4,330 dan berada pada kategori sangat tinggi. Sebaliknya, persepsi paling rendah dalam pertanyaan yang diajukan ada pada pertanyaan mengenai kebutuhan pengguna dengan bertanya langsung. Pada pertanyaan tersebut diperoleh rata-rata nilai 3,330 yang berada pada kategori sedang.

Tabel II

Persepsi Responden Pada Variabel Loyalitas

\begin{tabular}{|c|c|c|c|}
\hline No & Pernyataan & Rata-Rata & Keterangan \\
\hline 1 & $\begin{array}{l}\text { Saya selalu berkunjung ke Perpustakaan } \\
\text { Universitas Airlangga karena koleksi yang disediakan } \\
\text { dari sumber yang terpercaya (kredibel) dan koleksi } \\
\text { yang dimiliki cukup lengkap }\end{array}$ & 3,880 & Tinggi \\
\hline 2 & $\begin{array}{l}\text { Saya selalu berkunjung ke Perpustakaan } \\
\text { Universitas Airlangga karena layanan dan fasilitasnya } \\
\text { cocok untuk kegiatan akademik, mis. belajar dan } \\
\text { diskusi bersama }\end{array}$ & 4,280 & Sangat Tinggi \\
\hline 3 & $\begin{array}{l}\text { Saya akan berkunjung ke perpustakaan saat ada } \\
\text { acara-acara menarik, seperti: seminar, nonton } \\
\text { bersama, bazaar buku, dsb. }\end{array}$ & 3,820 & Tinggi \\
\hline 4 & $\begin{array}{l}\text { Saya akan merekomendasikan Perpustakaan } \\
\text { Universitas Airlangga terlebih dahulu apabila teman } \\
\text { atau pengguna lain membutuhkan koleksi / sumber } \\
\text { informasi lainnya }\end{array}$ & 3,980 & Tinggi \\
\hline 5 & $\begin{array}{l}\text { Saya akan mengajak teman } \text { saya atau } \\
\text { pengguna lain untuk berkunjung ke Perpustakaan } \\
\text { Universitas Airlangga apabila ada layanan/ fasilitas } \\
\text { terbaru }\end{array}$ & 3,990 & Tinggi \\
\hline 6 & $\begin{array}{l}\text { Saya akan memberitahukan daya tarik } \\
\text { Perpustakaan Universitas Airlangga kepada teman / } \\
\text { pengguna lain. }\end{array}$ & 4,020 & Tinggi \\
\hline 7 & $\begin{array}{l}\text { Saya akan berkomitmen untuk tetap menjadi } \\
\text { pengguna yang setia di Perpustakaan } \\
\text { Universitas Airlangga }\end{array}$ & 4,010 & Tinggi \\
\hline & Rata-Rata Variabel & 3,997 & Tinggi \\
\hline
\end{tabular}

Berdasarkan keterangan pada tabel di atas, dapat diketahui bahwa persepsi responden terhadap variabel loyalitas dengan 7 pertanyaan menghasilkan rata-rata nilai sebesar 3,997. Rata-rata persepsi tersebut berada pada kategori tinggi. Persepsi paling tinggi yang diberikan responden adalah pada indikator "Saya selalu berkunjung ke Perpustakaan Universitas Airlangga karena layanan dan fasilitasnya cocok untuk kegiatan akademik, mis. belajar dan diskusi bersama" dengan rata-rata 4,280 atau dalam kategori sangat tinggi. Sebaliknya, persepsi paling rendah yang diberikan responden adalah pada indikator "Saya akan berkunjung ke perpustakaan saat ada acara seperti seminar, nonton bersama, bazar buku, dsb" dengan rata-rata 3,820 yang masih berada pada kategori tinggi.

\section{- Uji Validitas Instrumen}


Uji validitas dilakukan dengan mengkorelasikan setiap skor item dengan skor total dengan menggunakan teknik Corrected Item-Total Correlation. Jika $\mathrm{r}$ tabel $<\mathrm{r}$ hitung maka valid, sebaliknya jika $\mathrm{r}$ table $>\mathrm{r}$, maka hasil tidak valid. Pada $\mathrm{r}$ tabel signifikansi 5\% (0.05) dengan uji dua sisi dan jumlah responden sebanyak $100(\mathrm{~N}=100)$ atau df $=98$, akan didapat $r$ tabel sebesar 0.1966

Tabel III

Hasil Pengujian Validitas Variabel Loyalitas

\begin{tabular}{|c|c|c|c|}
\hline Item Pernyataan & $\begin{array}{c}\text { Koefisien } \\
\text { Korelasi }\end{array}$ & $\begin{array}{r}r \text { tabel } \\
N=100 \\
a=0.05\end{array}$ & Keterangan \\
\hline $\begin{array}{l}\text { Saya merasa bahwa pustakawan perpustakaan } \\
\text { Universitas Airlangga memberikan pelayanan yang baik } \\
\text { kepada pengguna }\end{array}$ & 0,494 & 0,1966 & Valid \\
\hline $\begin{array}{l}\text { Saya merasa bahwa } \text { pustakawan perpustakaan } \\
\text { Universitas Airlangga selalu memberikan senyum, salam, } \\
\text { sapa kepada pengguna }\end{array}$ & 0,498 & 0,1966 & Valid \\
\hline $\begin{array}{l}\text { Saya merasa bahwa pustakawan perpustakaan Universitas } \\
\text { Airlangga memiliki sikap sopan dan santun kepada } \\
\text { pengguna }\end{array}$ & 0,613 & 0,1966 & Valid \\
\hline $\begin{array}{l}\text { Saya merasa bahwa sikap ramah yang diberikan } \\
\text { Pustakawan Perpustakaan Universitas Airlangga mampu } \\
\text { menciptakan suasana yang nyaman saat menggunakan } \\
\text { layanan di perpustakaan }\end{array}$ & 0,484 & 0,1966 & Valid \\
\hline $\begin{array}{l}\text { Saya merasa bahwa Pustakawan Perpustakaan } \\
\text { Universitas Airlangga sigap dalam membantu pengguna yang } \\
\text { mengalami kesulitan dalam mencari sumber informasi }\end{array}$ & 0,383 & 0,1966 & Valid \\
\hline $\begin{array}{l}\text { Saya merasa bahwa Pustakawan Perpustakaan } \\
\text { Universitas Airlangga berusaha untuk mengetahui kebutuhan } \\
\text { pengguna dengan bertanya secara langsung kepada pengguna }\end{array}$ & 0,399 & 0,1966 & Valid \\
\hline $\begin{array}{l}\text { Saya merasa bahwa } \quad \text { Pustakawan Perpustakaan } \\
\text { Universitas Airlangga mampu dalam memenuhi kebutuhan } \\
\text { pengguna. }\end{array}$ & 0,499 & 0,1966 & Valid \\
\hline $\begin{array}{l}\text { Saya merasa bahwa Pustakawan Perpustakaan } \\
\text { Universitas Airlangga telah menyediakan koleksi yang cukup } \\
\text { lengkap, baik dari }\end{array}$ & 0,342 & 0,1966 & Valid \\
\hline $\begin{array}{l}\text { Saya merasa bahwa Pustakawan Perpustakaan Universitas } \\
\text { Airlangga telah melayani pengguna dengan cepat dan tepat }\end{array}$ & 0,638 & 0,1966 & Valid \\
\hline $\begin{array}{l}\text { Saya merasa bahwa Pustakawan Perpustakaan } \\
\text { Universitas Airlangga selalu memberikan informasi baru (up } \\
\text { to date) } \\
\text { kepada pengguna, baik secara offline maupun online }\end{array}$ & 0,522 & 0,1966 & Valid \\
\hline $\begin{array}{l}\text { Saya merasa bahwa Pustakawan Perpustakaan } \\
\text { Universitas Airlangga sudah berinteraksi dengan baik dan } \\
\text { aktif kepada para pengguna secara offline maupun online }\end{array}$ & 0,561 & 0,1966 & Valid \\
\hline $\begin{array}{l}\text { Saya merasa bahwa } \\
\text { Universitas Airlangga masih mempertahankan sumber } \\
\text { informasi untuk generasi tua (baby boomers), mis. kebutuhan } \\
\text { koleksi cetak }\end{array}$ & 0,458 & 0,1966 & Valid \\
\hline
\end{tabular}




\begin{tabular}{|c|c|c|c|}
\hline $\begin{array}{l}\text { Saya merasa bahwa } \\
\text { Universitas Airlangga mampu menyesuaikan kebutuhan } \\
\text { sumber informasi untuk generasi muda } \\
\text { mis. kebutuhan koleksi digital }\end{array}$ & 0,451 & 0,1966 & Valid \\
\hline $\begin{array}{l}\text { Saya merasa bahwa layanan music coustic di waktu } \\
\text { tertentu dapat dinikmati oleh pengguna saat berada di } \\
\text { Perpustakaan Universitas Airlangga }\end{array}$ & 0,404 & 0,1966 & Valid \\
\hline $\begin{array}{l}\text { Saya merasa bahwa layanan music coustic yang ada di } \\
\text { Perpustakaan Universitas Airlangga mampu } \\
\text { menciptakan suasana santai kepada pengguna }\end{array}$ & 0,407 & 0,1966 & Valid \\
\hline $\begin{array}{l}\text { Saya merasa bahwa Perpustakaan Universitas Airlangga } \\
\text { memiliki warna interior yang bagus dan nyaman untuk } \\
\text { dilihat }\end{array}$ & 0,585 & 0,1966 & Valid \\
\hline $\begin{array}{l}\text { Saya merasa bahwa pemilihan warna interior di } \\
\text { Perpustakaan Universitas Airlangga mampu menciptakan } \\
\text { suasana yang betah dan nyaman saat berada di } \\
\text { perpustakan }\end{array}$ & 0,567 & 0,1966 & Valid \\
\hline $\begin{array}{l}\text { Saya merasa bahwa Perpustakaan Universitas Airlangga } \\
\text { memiliki pencahayaan ruangan yang baik }\end{array}$ & 0,629 & 0,1966 & Valid \\
\hline $\begin{array}{l}\text { Saya merasa } \\
\text { Perpustakaan Universitas Airlangga sudah bagus dan cocok }\end{array}$ & 0,569 & 0,1966 & Valid \\
\hline $\begin{array}{l}\text { Saya merasa bahwa Pustakawan Perpustakaan } \\
\text { Universitas Airlangga menyediakan fasilitas lemari minuman } \\
\text { dingin untuk memenuhi kebutuhan pengguna saat berada di } \\
\text { dalam perpustakaan }\end{array}$ & 0,460 & 0,1966 & Valid \\
\hline $\begin{array}{l}\text { Saya merasa bahwa Perpustakaan Universitas Airlangga } \\
\text { memiliki ruangan yang sejuk, bersih dan terawat }\end{array}$ & 0,575 & 0,1966 & Valid \\
\hline $\begin{array}{l}\text { Saya merasa bahwa Perpustakaan Universitas Airlangga } \\
\text { memiliki interior (mis. Rak, meja, kursi, dll) yang bersih dan } \\
\text { terawat }\end{array}$ & 0,602 & 0,1966 & Valid \\
\hline $\begin{array}{l}\text { Saya merasa bahwa Perpustakaan Universitas Airlangga } \\
\text { memiliki kursi/sofa dan karpet yang empuk dan nyaman }\end{array}$ & 0,600 & 0,1966 & Valid \\
\hline $\begin{array}{l}\text { Saya merasa bahwa desain interior yang digunakan di } \\
\text { ruang Perpustakaan Universitas Airlangga memiliki desain } \\
\text { yang bagus dan indah }\end{array}$ & 0,622 & 0,1966 & Valid \\
\hline $\begin{array}{llrr}\text { Saya merasa bahwa } & \text { desain interior di Perpustakaan } \\
\text { Universitas Airlangga } & \text { selalu diperbarui } & \text { mengikuti } \\
\text { perkembangan zaman } & & & \end{array}$ & 0,539 & 0,1966 & Valid \\
\hline $\begin{array}{l}\text { Saya merasa bahwa desain dan tata ruang yang ditampilkan } \\
\text { di ruang Perpustakaan Universitas Airlangga mampu } \\
\text { menciptakan suasana betah dan nyaman }\end{array}$ & 0,705 & 0,1966 & Valid \\
\hline $\begin{array}{l}\text { Saya merasa bahwa desain situs web Perpustakaan } \\
\text { Universitas Airlangga memiliki desain yang simpel dan } \\
\text { bagus }\end{array}$ & 0,497 & 0,1966 & Valid \\
\hline $\begin{array}{l}\text { Saya merasa bahwa desain situs web } \text { Perpustakaan } \\
\text { Universitas Airlangga nyaman untuk dilihat }\end{array}$ & 0,592 & 0,1966 & Valid \\
\hline
\end{tabular}

Berdasarkan Tabel III yang memuat hasil pengujian validitas variabel emotional branding, dapat dilihat bahwa nilai atau $\mathrm{r}$ tabel $<\mathrm{r}$ hitung, maka seluruh item pernyataan dinyatakan valid. 
Tabel IV

Hasil Pengujian Reliabilitas

\begin{tabular}{|l|c|c|c|}
\hline \multicolumn{1}{|c|}{ Variabel } & Cronbach Alpha & Cut Off & Keterangan \\
\hline Hubungan $\left(\mathrm{X}_{1}\right)$ & 0,854 & 0,600 & Reliabel \\
\hline Pengalaman Pancaindra $\left(\mathrm{X}_{2}\right)$ & 0,866 & 0,600 & Reliabel \\
\hline Imajinasi $\left(\mathrm{X}_{3}\right)$ & 0,827 & 0,600 & Reliabel \\
\hline Loyalitas $(\mathrm{Y})$ & 0,832 & 0.600 & Reliabel \\
\hline
\end{tabular}

Berdasarkan table di atas, dapat diketahui bahwa nilai semua variabel mempunyai Cronbach alpha yang lebih besar dari 0,600 , sehingga indikator pada masing-masing variabel dinyatakan layak.

Tabel V

Hasil Uji Multikolineritas

\begin{tabular}{|c|c|c|}
\hline Model & Nilai Tolerance & VIF \\
\hline $\mathrm{X}_{1}$ & 0,630 & 1,658 \\
\hline $\mathrm{X}_{2}$ & 0,506 & 1,977 \\
\hline $\mathrm{X}_{3}$ & 0,485 & 2,062 \\
\hline
\end{tabular}

Berdasarkan data pada Tabel V, diketahui bahwa tidak ada variabel yang memiliki VIF lebih dari 10, maka dapat dinyatakan bahwa tidak ada gejala multikolinearitas antar variabel independen dalam penelitian ini.

Asumsi Normalitas

Hipotesis pada pengujian asumsi normalitas adalah sebagai berikut:

$\mathrm{H}_{0}$ : Residual berdistribusi normal

H1: Residual tidak berdistribusi normal

Kriteria pengujian menyatakan apabila nilai probabilitas Saphiro Wilk's lebih besar dari nilai significant alpha 5\% atau 0,05, maka dinyatakan berdistribusi normal.

Tabel VI

Pengujian Normalitas Melalui Pengujian Saphiro Wilk's

\begin{tabular}{|c|c|c|}
\hline V & Saphiro Wilk's & Probabilit \\
\hline Hubungan (X1) & 0 & 0 \\
\hline Pengalaman pancaindra & 0 & 0 \\
\hline Imajinasi (X3) & 0 & 0 \\
\hline Loyalitas (Y) & 0 & 0 \\
\hline R & 0 & 0 \\
\hline
\end{tabular}

Berdasarkan Pengujian asumsi normalitas menghasilkan probabilitas statistik uji Saphiro Wilk's pada variabel hubungan (X1) dan imajinasi (X3) lebih kecil dari nilai significant alpha 5\% atau 0,05 sehingga $\mathrm{H}_{0}$ ditolak dan residual pada model pengaruh hubungan $\left(\mathrm{X}_{1}\right)$ dan imajinasi $\left(\mathrm{X}_{3}\right)$ terhadap loyalitas $(\mathrm{Y})$ dinyatakan tidak berdistribusi normal. $\mathrm{V}$ ariabel pengalaman pancaindra $\left(\mathrm{X}_{2}\right)$ menghasilkan probabilitas lebih besar yaitu $0,083>0,05$ maka dapat dinyatakan berdistribusi normal dan untuk variabel Loyalitas $(\mathrm{Y})$ 
menghasilkan probabilitas statistik uji Saphiro Wilk's lebih kecil dari nilai significant alpha 5\% atau 0,05 sehingga $\mathrm{H}_{0}$ ditolak. Hal ini berarti loyalitas (Y) dinyatakan tidak berdistribusi normal. Hal ini berarti analis Korelasi Pearson tidak dapat dilakukan, sehingga menggunakan Korelasi Spearman sebagai alternatifnya.

Tabel VII

Pengujian Heteroskedastisitas

\begin{tabular}{|c|c|c|}
\hline Variabel & T Statistics & Prob. \\
\hline Hubungan $\left(\mathrm{X}_{1}\right)$ & 0,616 & 0,539 \\
\hline Pengalaman & $-0,505$ & 0,615 \\
\hline Imajinasi $\left(\mathrm{X}_{3}\right)$ & $-0,765$ & 0,446 \\
\hline
\end{tabular}

Pengujian asumsi heteroskedastisitas menunjukkan bahwa variabel bebas pada model menghasilkan probabilitas lebih besar dari level of significant ( $\alpha=5 \%$ atau 0.05 ). Hal ini berarti residual dinyatakan memiliki ragam yang homogen, dengan demikian asumsi heteroskedastisitas terpenuhi.

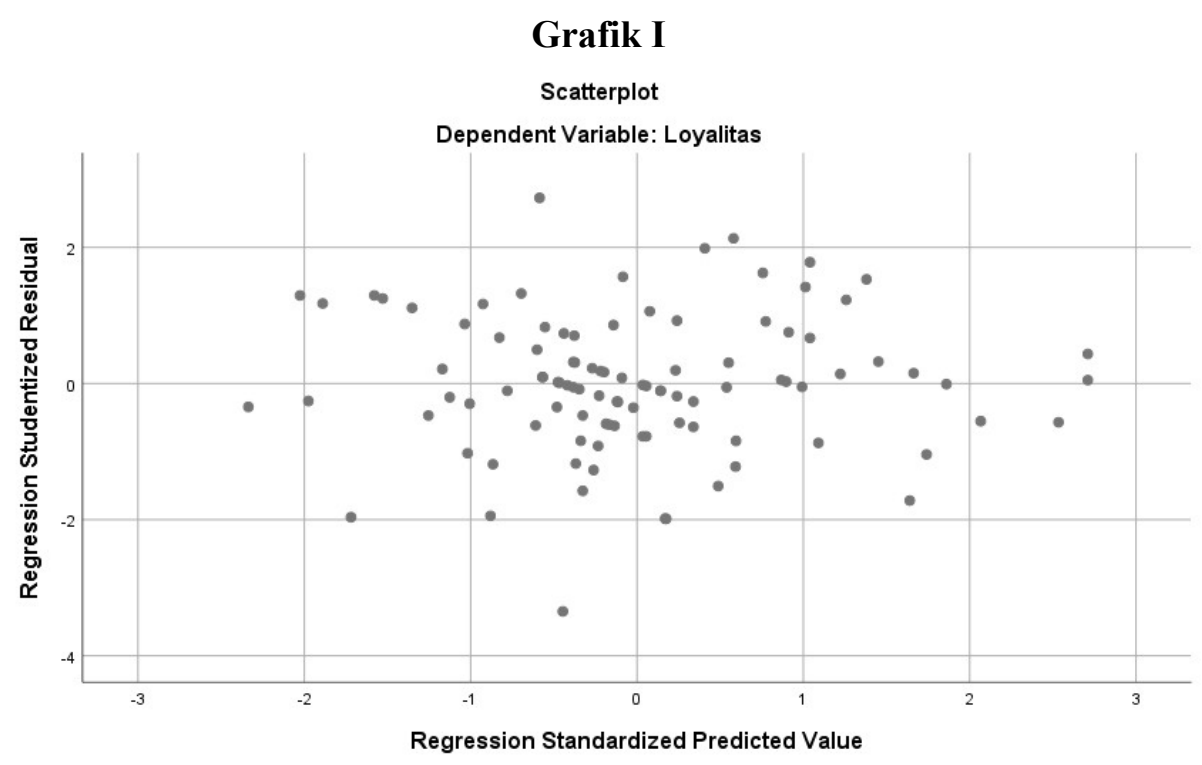

Berdasarkan grafik I scatterplot, titik-titik menyebar di sekitar angka 0 , berada di atas dan di bawah. Persebaran titik-titik data tidak boleh membentuk pola bergelombang, melebar, kemudian menyempit, dan melebar kembali, sehingga residual dinyatakan memiliki ragam yang homogen. Dengan demikian asumsi heteroskedastisitas terpenuhi.

\section{- Uji Hipotesis}

Tabel VIII

Analisis Korelasi Spearman

\begin{tabular}{|c|c|c|c|}
\hline Variabel X & Variabel Y & Koefisien Korelasi & Sig. \\
\hline Emotional branding & Loyalitas & 0,588 & 0,000 \\
\hline Hubungan $\left(\mathrm{X}_{1}\right)$ & Loyalitas & 0,561 & 0,000 \\
\hline
\end{tabular}




\begin{tabular}{|c|c|c|c|}
\hline $\begin{array}{c}\text { Pengalaman pancaindra } \\
(\mathrm{X})\end{array}$ & Loyalitas & 0,471 & 0,000 \\
\hline Imajinasi $\left(\mathrm{X}_{3}\right)$ & Loyalitas & 0,480 & 0,000 \\
\hline
\end{tabular}

Dari Tabel VIII di atas, dapat diketahui bahwa hasil pengujian emotional branding dengan loyalitas menunjukkan bahwa probabilitas < significant alpha (5\%). Ini berarti ada hubungan yang signifikan antara emotional branding dengan loyalitas. Koefisien hubungan emotional branding dengan loyalitas sebesar 0,588 (positif), ada hubungan erat antara emotional branding dengan Loyalitas dalam kategori sedang, dan koefisien yang positif menunjukkan hubungan yang searah. Kesimpulannya adalah peningkatan emotional branding diikuti dengan peningkatan loyalitas. Hubungan variabel hubungan $\left(\mathrm{X}_{1}\right)$ dengan loyalitas menghasilkan koefisien korelasi sebesar 0,561 dengan probabilitas sebesar 0,000 yang berarti terdapat hubungan yang signifikan antara aspek hubungan $\left(\mathrm{X}_{1}\right)$ dengan loyalitas. Koefisien hubungan aspek hubungan $\left(\mathrm{X}_{1}\right)$ dengan loyalitas sebesar 0,561 (positif) menunjukkan bahwa keeratan hubungan aspek hubungan dengan loyalitas dalam kategori sedang, dan koefisien yang positif menunjukkan hubungan yang searah. Hal yang sama juga berlaku pada hubungan antara aspek pengalaman pancaindra $\left(\mathrm{X}_{2}\right)$ dengan imajinasi $\left(\mathrm{X}_{3}\right)$ yang masing-masing koefisien korelasi didapatkan 0,471 dan 0,480 dengan probabilitas 0,000 . Hal tersebut berarti terdapat hubungan yang signifikan antara aspek pengalaman pancaindra dan imajinasi dengan loyalitas. Koefisien kedua aspek juga bernilai positif. Hal ini menunjukkan bahwa keeratan kedua aspek dengan loyalitas dalam kategori sedang, dan koefisien yang positif menunjukkan hubungan yang searah.

\section{PENUTUP}

\section{KESIMPULAN}

Dengan berbagai proses pengujian, ditemukan pengaruh emotional branding terhadap loyalitas. Berdasarkan hasil korelasi Spearman, koefisien korelasi didapatkan sebesar 0,588 dengan probabilitas sebesar 0,000. Hasil pengujian tersebut menunjukkan bahwa probabilitas < significant alpha (5\%). Dari hasil tersebut dapat dinyatakan bahwa terdapat pengaruh yang signifikan antara emotional branding dengan loyalitas, dengan koefisien sebesar 0,588 (positif). Hal ini menunjukkan bahwa keeratan pengaruh emotional branding dengan loyalitas dalam kategori sedang, dan koefisien yang positif menunjukkan hubungan yang searah, yang artinya peningkatan emotional branding diikuti dengan peningkatan loyalitas.

\section{SARAN}

Semakin besar upaya Perpustakaan untuk meningkatkan pelayanan yang berkaitan dengan emotional branding, semakin besar pula loyalitas pemustaka pada perpustakaan. Hal ini menepis ketakutan akan terpinggirkannya perpustakaan karena perkembangan teknologi. Ada banyak layanan yang disediakan oleh perpustakaan dan Pustakawan, yang tidak bisa didapatkan dalam mesin pencari google atau aplikasi lain. Hal ini sekaligus mengikat pemustaka untuk datang meski tidak dalam kebutuhan untuk mencari informasi. Layanan yang disediakan seperti American Corner, Great Britain Corner, Warung Perancis, dan 
fasilitas lainnya membuat pemustaka tetap ingin mengunjungi perpustakaan untuk merasakan suasana emosional.

\section{DAFTAR PUSTAKA}

Akbar, M. M., \& Parvez, N. (2009). Impact Of Service Quality, Trust, And Customer Mohammad Muzahid Akbar and Noorjahan Parvez. ABAC Journal, 29(1), 24-38.

Akgün, A. E., Koçoğlu, İ., \& İmamoğlu, S. Z. (2013). An Emerging Consumer Experience: Emotional Branding. Procedia - Social and Behavioral Sciences, 99, 503-508. https://doi.org/10.1016/j.sbspro.2013.10.519

Furfey, P. H., \& Siegel, S. (1957). Nonparametric Statistics for the Behavioral Sciences. The American Catholic Sociological Review. https://doi.org/10.2307/3708383

Ghozali;, I. (2013). Aplikasi Analisis Multivariate dengan Program IBM SPSS 21 Update PLS Regresi. //mikroskil.ac.id/pustaka/index.php? $\mathrm{p}=$ show_detail\&id=7026\&keywords= Gobe, M. (2001). Making the emotional connection. Brandweek.

Gobe, Marc. (n.d.). Emotional Branding: The New Paradigm for Connecting Brands to People - Marc Gobe - Google Buku. Penerbit Erlangga. Retrieved November 18, 2020, from https://books.google.co.id/books?hl=id\&lr=\&id=fmmCDwAAQBAJ\&oi=fnd\&pg=PT12 $\& d q=$ emotional + branding\&ots $=$ amQSjFFvZ5\&sig $=$ GNsB7FLjxswWTWCGsFV1GN5fzY\&redir_esc $=\mathrm{y} \# \mathrm{v}=$ onepage $\& \mathrm{q}=$ emotional branding $\& \mathrm{f}=$ false Gobe, Marc. (2003). Emotional identity. In Global Cosmetic Industry.

Herlina, V. (2019). Panduan Praktis Mengolah Data Kuesioner Menggunakan SPSS - Vivi Herlina - Google Buku. Elex Meida Komputindo.

Kahle, L. R., \& Malhotra, N. K. (1994). Marketing Research: An Applied Orientation. In Journal of Marketing Research (Vol. 31, Issue 1). https://doi.org/10.2307/3151953

Kim, Y. K., \& Sullivan, P. (2019). Emotional branding speaks to consumers' heart: the case of fashion brands. Fashion and Textiles, 6(1). https://doi.org/10.1186/s40691-018-0164-y

Kustini, N. I. (2011). Experiential Marketing, Emotional Branding, and Brand Trust and Their Effect on Loyalty on Honda Motorcycle Product. Journal of Economics, Business, and Accountancy | Ventura, 14(1), 19-28. https://doi.org/10.14414/jebav.v14i1.12

Papulova, Z. (2014). The Significance of Vision and Mission Development for Enterprises in Slovak Republic. Journal of Economics, Business and Management. https://doi.org/10.7763/joebm.2014.v2.90

Pogorzelski, J. (2018). Emotional Branding. Managing Brands in 4D, February, 59-109. https://doi.org/10.1108/978-1-78756-102-120181004

Pratiwi, V. aulia. (2016). Pengaruh Emotional Branding Terhadap Loyalitas Konsumen Wanita Pada Produk Shampo Pantene.

Priyono. (2012). Metode Penelitian Kuantitatif. In Zifatama (Vol. 66).

Rubin, R. (2010). Foundations of library and information science (3rd ed.). Neal-Schuman Publishers.

Saini, S., \& Singh, J. (2017). Cultivating Emotional Branding Through Customer Experience Management. 55-71. https://doi.org/10.4018/978-1-5225-2921-7.ch004 
Santoso, S. (2019). Statistik Parametrik. Statmat : Jurnal Statistika Dan Matematika.

Setiadi, G., Djoko, H., \& Ngatno, W. (2015). Pengaruh emotional branding, nilai pelanggan, dan citra merek terhadap loyalitas pelanggan melalui kepuasan pelanggan J . CO Java Mall Semarang. Jurnal Administrasi Bisnis, 4(4), 1-14.

https://ejournal3.undip.ac.id/index.php/jiab/article/view/9230

Sugiyono. (2014). Metode Penelitian Pendidikan pendekatan Kuantitatif, Kualitatif dan R\&D. In METODE PENELITIAN ILMIAH.

Tajedini, O., Khasseh, A. A., Afzali, M., \& Sadatmoosavi, A. (2020). How to increase the loyalty of public library pemustakas? A qualitative study. Journal of Librarianship and Information Science. https://doi.org/10.1177/0961000619856081

Unaradjan, D. D., \& Sihotang, K. (2019). Metode Penelitian Kuantitatif. Penerbit Unika Atma Jaya Jakarta.

Wijanarka, Y., Suryoko, S., \& Widiartanto. (2014). Pengaruh Emotional branding dan Experiential marketing Terhadap Loyalitas Merek Eiger Adventure Melalui Brand trust dan Kepuasan Pelanggan Sebagai Variabel Intervening (Studi Kasus Pada Eiger Adventure Store Semarang). Diponegoro Journal Of Social And Political Of Science, 112. http://ejournal-s1.undip.ac.id/index.php/\%0A“Pengaruh 